\title{
Improving the efficiency of crystalline silicon solar cell through regulating their temperature using thin films of polyvinyl alcohol
}

\author{
Ali Kadhim Naser ${ }^{1, *}$, Dhafer Manea.Hachim ${ }^{1}$, and Qahtan A Abed ${ }^{2}$ \\ ${ }^{1}$ Engineering Technical College / Najaf, Al-Furat Al-Awsat Technical University, 31001 Najaf, Iraq. \\ ${ }^{2}$ Technical Institute/ Al-Rumaitha, Al - Furat Al- Awsat Technical University, 31001 Najaf, Iraq.
}

\begin{abstract}
Rising temperatures significantly affect the PV module, decreasing its voltage and lowering output power. Furthermore, temperature rises have been linked to several PV module failures or degradation modes. The purpose of this study analyzes polyvinyl alcohol PVA on crystalline silicon solar cells as a thermal insulation thin film. PVA thin films were prepared by dip-coating technique with a thickness of $1.15 \mu \mathrm{m}$. The films exhibit suitable solar cell temperature controlling though it's an effect on masking the ultraviolet wavelength. The maximum temperature variation on the coating solar cell's surface was $4.5^{\circ} \mathrm{C}$ as a comparison to a bare solar cell with irradiate exposure time $1800 \mathrm{sec}$, and maximum efficiency obtained $18.99 \%$ in which $\mathrm{Voc}=0.566 \mathrm{v}$ and Isc $=$ $330.2 \mathrm{~mA}$ when compared with bare solar cell $15.07 \%$ with benefit efficiency $+3.92 \%$. The concentrations of the polyvinyl alcohol influences on thin films and their effect on solar cell parameters are discussed.
\end{abstract}

Keywords: UV-mask, polycrystalline solar cells, surface temperature controlling system.

\section{Introduction}

Because of the rising cost of oil-based electricity, the termination of fossil fuel resources, and the contamination of the atmosphere, renewable energy sources have recently attracted a lot of interest. For these reasons, countries have been encouraged to replace fossil fuels with new energy sources, such as solar energy. Crystalline silicon solar cells are the earliest solar cell technologies to be developed, and it is still the most widely used type [1]. Via photovoltaic processes, Solar cells convert sunlight directly into electricity. In photovoltaic cells, semiconductors convert light to electricity since the semiconductor absorbs enough energy from light photons. The absorbed energy aids in the Excitation and transition of an electron from its valance to its conduction band; thus, an electron-hole couple is created (exactions) [2]. The generated electrical current is carried through a $\mathrm{P} / \mathrm{N}$ junction in the solar cell. Consequently, only photons of the same to or beyond the bandgap energy are involved. When the photon's energy exceeds the bandgap energy, electrons are freed, and the excess is radiated as heat, elevating the solar cell temperature. Consequently, The Excitation of the semi-conduction of light electrons causes the generation of electrical current and heat in solar cells. You can achieve maximum

* Corresponding author: alikadhim558@,gmail.com 
power efficiency by consuming the entire solar spectrum within the band of that range without loss of power. In today's technological world, UV irradiation protection is a significant concern. The action of photonic energy in non-UV protective materials can cause undesired breakage of chemical structures, and it may be toxic to living organisms; Photo-aging of the skin can occur under intense ultraviolet light [3]. When it comes to UV radiation, it is usually divided into UV-A, UV-B, and UVC radiation, with wavelengths ranging from $315-380 \mathrm{~nm}$ to $280-315 \mathrm{~nm}$ and from $100-280 \mathrm{~nm}$, respectively. UVC light rays with energy levels of approximately $4.43-4.4 \mathrm{eV}$ cause more harm than UVA and UVB rays of approximately $3.94-4.4 .43 \mathrm{eV}$. Ultra-violet-blocking substances are thus required to help in reducing damage. Via strengthening inorganic fillers into a transparent polymer matrix, these materials can be customized to achieve a bandgap in the desired region that may help block UV rays even further [4]. Solutions or fine powder polymeric films are needed to make realistic use of these materials. Since reinforced polymers have the added advantage of being UV-protective shields, inorganic nanoparticles (which can cut UV absorption) can be incorporated into a polymer. (Enhancing their properties), rendering them significantly more effective in day-to-day life. A small amount of inorganic matter can improve the polymer matrix's versatility in thermo-mechanical, optoelectronic, and mechanical properties [5].

The cost efficiency and biocompatibility of polyvinyl alcohol (PVA) have made it an appealing alternative to other polymer film-forming additives. PVA's chemical formula is $\left[\mathrm{CH}_{2}-\mathrm{CH}(\mathrm{OH})\right] \mathrm{n}$, with $\mathrm{n}$ indicating the degree of polymerization [6].

Aslam M, Kalyar MA study the effect and investigate the impact of an organic semiconductor. Polymer - polyvinyl-alcohol PVA has been widely used for Ultraviolet protection due to its characteristic nature, i.e., UV scattering and absorbing nature, broadband UV absorption, and excellent stability against high temperature and Ultraviolet rays [7]. Polyvinyl alcohol is a renowned semi crystalline polymer that comes from the $\mathrm{OH}$ group and hydrogen bonding feature. It has a high aspect ratio, a high ultimate tensile power, a high modulus of elasticity, and is chemically compatible [8]. Polymers have the property of absorbing ultraviolet-B radiation in general of solar photons [9]. Polymeric nanocomposites produced from polyvinyl alcohol) (PVA) have become a prime candidate for hydroxylation, which permits the usage of polymerization through hydrogen bonding to Nano well composition to the molecular level because they possess a vast number of hydroxyl groups adjoined to their carbon backbone [10,11]. The structural, transparent, thermally stable, optical, UV shielding, mechanical and good forming film characteristics of polyvinyl alcohol make it a good insulation film and fit for different application in general and solar cells in especial $[12,13]$.

PVA thin films were prepared on a silicon substrate in this work using a dip-coating technique. UV-Vis Spectroscopy, solar cell analyzer module, and thermo-couples K-type with data-logger PC-link were used for optical properties and thermal studies. These films are excellent UV-BLOCK and thermal insulators for solar cells, and they extend the life of the solar cell.

\section{Experimental set-up}

The $4 \mathrm{~cm} \times 2 \mathrm{~cm}$ polycrystalline silicon solar cells used in this work illustrated in Figure 1; the samples first washed with ethanol used ultrasonic water bath type for 1 hour.

PVA (polyvinyl alcohol) had a polymerization frequency of 1700-1800, which was purchased from Sigma-Aldrich with molecular weight (Mw) from 2000 to $200000 \mathrm{~g} / \mathrm{mol}$. The solubility of PVA in water is influenced by the degree of hydrolysis and polymerization. The molecular weight of a polymer increases as the degree of 
polymerization rises, and it has been shown that the solubility of a polymer reduces as the molecular weight rises at a given temperature [12].

Sodium nitrate (Nano3) and Sodium dihydrogen phosphate $\left(\mathrm{NaH}_{2} \mathrm{PO}_{4}\right)$ with concentrations $0.2 \mathrm{M}$ and $0.01 \mathrm{M}$ respectively with a limited ratio of distillation water (DI) were used as a solvent to PVA at room temperature.

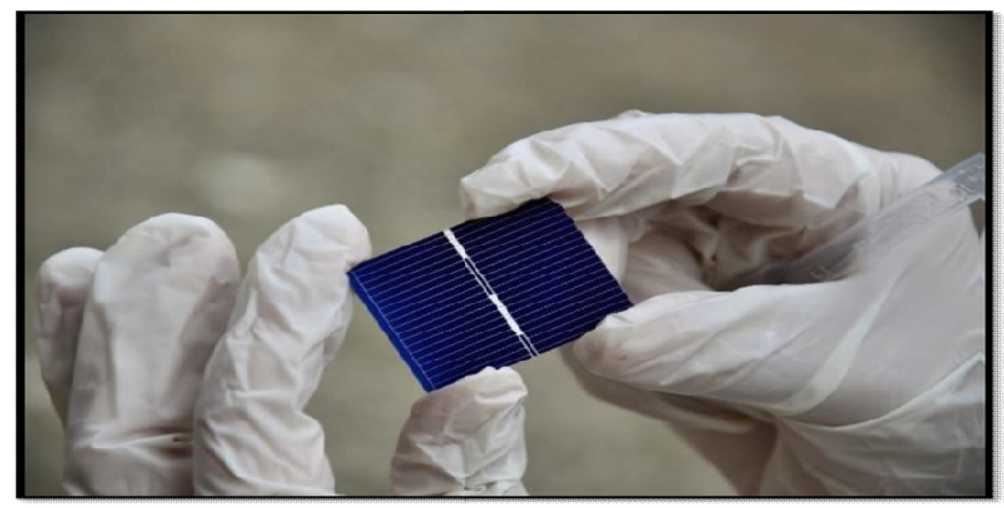

Fig .1. Mc-Si $(4 \mathrm{~cm} \times 2 \mathrm{~cm})$ solar cell.

\section{Experimental procedures}

The $125 \mathrm{ml}$ distillation water (DI), $2.125 \mathrm{~g}(\mathrm{NaNo} 3)$, and $0.145 \mathrm{~g}\left(\mathrm{NaH}_{2} \mathrm{PO}_{4}\right)$ were agitated in a magnetic stirrer for $1 \mathrm{hr}$ to get the best polymer-solvent at room temperature. Many concentrations of polyvinyl alcohol $(1.5 \mathrm{~g}, 1 \mathrm{~g}, 0.75 \mathrm{~g}, 0.5 \mathrm{~g}$, and $0.125 \mathrm{~g}$ ) for every $25 \mathrm{ml}$ of the solvent were prepared prior. The mixture stays on a magnetic stirrer $300 \mathrm{RPM}$ for $3 \mathrm{hr}$ at room temperature. Leave the solution to sit until foaming is finished and sealed tightly to avoid bacteria formation. Repeat the procedure five times to prepare all samples.

Deposition of the PVA GEL as a film on Si substrate via the dip-coating technique is one of the best and easiest techniques to control obtaining a uniform thin film. Industrial blower to dyer the sample used for $10-15 \mathrm{~min}$ at $1500{ }^{\circ} \mathrm{C}$.

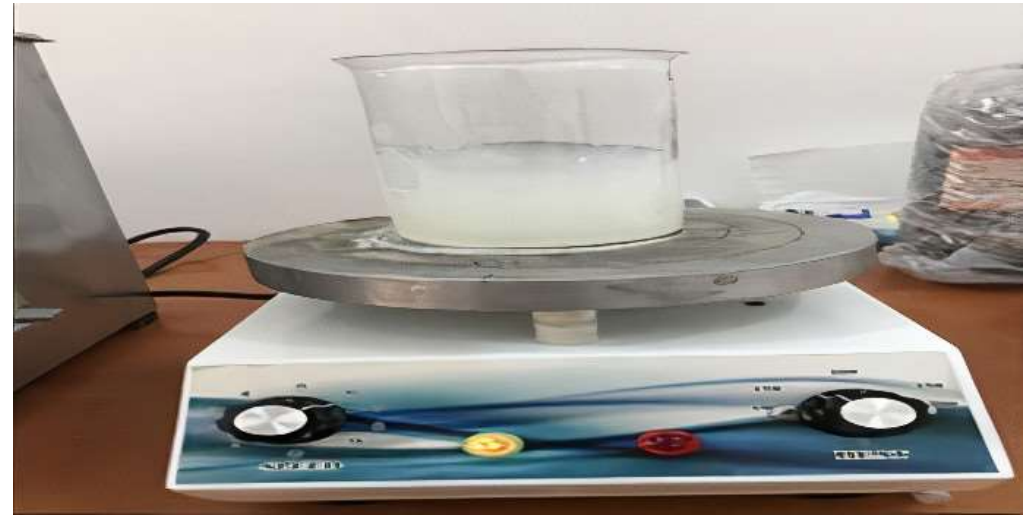

Fig.2. $125 \mathrm{ml}$ distillation water+ Poly vinyl alcohol+ Nano3 + NaH2PO4. 


\subsection{Thin-film thickness measurement}

The most common approach is using an electronic balance. The substrates were weighed before and after deposition. Differences in substrate thicknesses make up the dissimilarity. Thinness has been accurately measured using the new equation $[\mathrm{t}=(\Delta \mathrm{m} / \rho . \mathrm{a} . \mathrm{b})]$ [13]. Where (a) and (b) are the substrate dimensions, $\Delta \mathrm{m}$ is the substrate's mass variance, $\rho$ is the material's density, and (t) is the thickness of thin-film deposited.

Table .1. Substrate's dimensions, PVA density, and mass' variance

\begin{tabular}{|c|c|}
\hline Density (PVA) & $1.19 . \mathrm{g} / \mathrm{cm} 3$ \\
\hline a: substrate's length & $4 \mathrm{~cm}$ \\
\hline b: substrate's width & $2 \mathrm{~cm}$ \\
\hline $\begin{array}{c}\Delta \text { m: substrate's mass variance prior and } \\
\text { after deposition }\end{array}$ & $0.0011 \mathrm{gram}$ \\
\hline
\end{tabular}

After applying the substrate's parameters, the PVA thin-film thickness was measured to be $(1.15 \mu \mathrm{m})$. The other approach to measuring thin-film thickness is; use an (INSIZE) micrometre to measure the thickness of the prepared films. The less thickness that can measure is $1 \mu \mathrm{m}$. The device is calibrated before Initiation to measure the thickness of the layer. By measured before and after the coating process and by knowing the difference between the two measurements, $\Delta \mathrm{ms}$ were obtained. Several readings of several positions are taken on the base's surface to get a more accurate thickness and take the average for those readings. The average thin-film thickness obtained was $(1.156 \mu \mathrm{m})$.

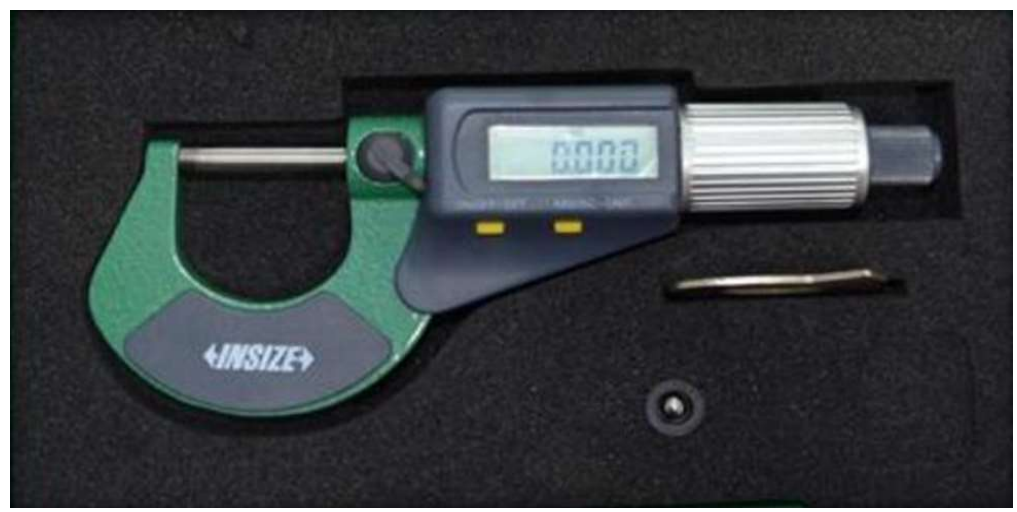

Fig.3. thin-film measurement device (INSIZE).

\section{Results and Discussion}

\subsection{Optical characteristics}

As the simplest component of matter, the atom or molecule has energy levels. The atom's electrons are in a stable state at room temperature within a level called the lower energy level. Electron's Excitation and this transition of the atom to high energy level are associated with whether the incident photon's energy is equal to the difference in energy between the two levels (the lower and the excitation levels) [14]. If the rays fall on a transparent part, part of this incident rays passes out from the other side. An absorption ray 
is a difference between incident and transmitted rays. The atoms absorb a specific spectrum of UV-Vis. The higher the concentration quantity represents, the more significant the absorption intensity. Figure 4 shows the absorption spectrum of a polymer with different concentrations of VS intensities. PVA has been presented as a promising optoelectronic candidate. Optical properties studies by UV-Vis's spectroscope indicated the absorption broad in the range $250-350 \mathrm{~nm}$, as shown in Figure 4. Absorption intensity increase with increasing the PVA concentrations maximum peak occurs at $0.2 \mathrm{~g}$ at $300 \mathrm{~nm}$. The conclusion from the data is clear: there is no absorption in the visible region in PVA film. PVA can absorb UV light, transmit visible light, and filter out UV light.

Polymer PVA is an Organic semiconductor with a wide energy gap of $3 \mathrm{eV}$. Molecules are bound to each other by weak van der Waals forces, whereas conjugated $\pi$-bonds bond atoms within an organic semiconductor. This molecular structure gives organic semiconductors their flexibility, lightweight, and low sublimation point. The HOMO and LUMO molecular orbitals are like the valence band and conduction band, respectively [3].

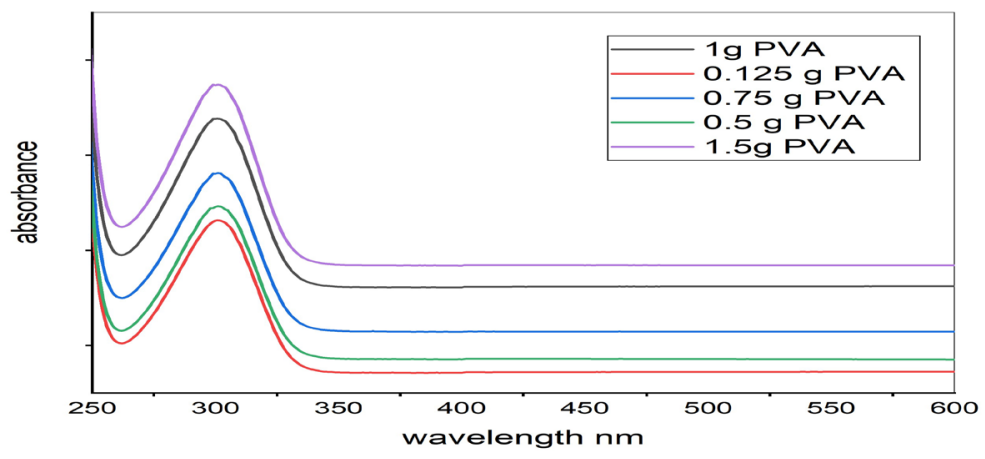

Fig. 4. UV-Vis represent the absorption of PVA for different concentrations.

\subsection{Thermal studies and temperature effect}

The temperature has a significant effect on solar cells. This is evidence of the loss of photovoltaic (PV) efficiency and energy yield because of the rise in panel temperature [16]. The Solar cells operating in harsh sunlight will experience a panel temperature of $50-70^{\circ} \mathrm{C}$, which will cause a reduction in efficiency of 10-25 percent [17].

The molecule contains, in addition to levels of electronic energy; there are levels of vibrational energy and rotation. As a result of the molecular bonding with chemical bonds, the absorbed energy leads to the vibration of these bonds and thus the vibration of the atoms concerning each other. As for the rotational energy levels, they appear due to the rotation of the molecule around its axis. These transitions are closely related to the intensity and energy of the incident rays, wherein in the ultraviolet region, all the aforementioned transitions appear. The excited electron returns to a stable state due to the loss of energy that is absorbed in the form of emitted radiation or lost as a result of a collision of atoms with each other, which results in a rise in temperature $[15,18]$.

This work used a data logger and thermo-couples K-types and halogen lamp with normal incident rays, its intensity $1000 \mathrm{~W} / \mathrm{m}^{2}$ for 1800 secs. It is clear from the figure below Fig. 5 that the cell with a higher concentration has a large temperature variation than a bare solar cell because of the UV wavelength effect, which has high frequency, high energy. The excess energy from raising the electron from the valence beam to the 
conduction beam and the flow of current would be dissipated in the form of heat, causing the cell surface temperature to rise.

Table.2. Temperature regulation with time for mc-Si coating and without coating solar cells.

\begin{tabular}{|c|c|c|c|}
\hline samples & Concentrations & Temperature variations & Time \\
\hline $\mathrm{S} 1$ & Bare & ----- & $1800 \mathrm{sec}$ \\
\hline $\mathrm{S} 2$ & $1.5 \mathrm{~g}$ & $4.5^{\circ} \mathrm{C}$ & $1800 \mathrm{sec}$ \\
\hline $\mathrm{S} 3$ & $1 \mathrm{~g}$ & $3.8^{\circ} \mathrm{C}$ & $1800 \mathrm{sec}$ \\
\hline $\mathrm{S} 4$ & $0.75 \mathrm{~g}$ & $2.3^{\circ} \mathrm{C}$ & $1800 \mathrm{sec}$ \\
\hline $\mathrm{S} 5$ & $0.5 \mathrm{~g}$ & $1.6^{\circ} \mathrm{C}$ & $1800 \mathrm{sec}$ \\
\hline $\mathrm{S} 6$ & $0.125 \mathrm{~g}$ & $0.9^{\circ} \mathrm{C}$ & $1800 \mathrm{sec}$ \\
\hline
\end{tabular}

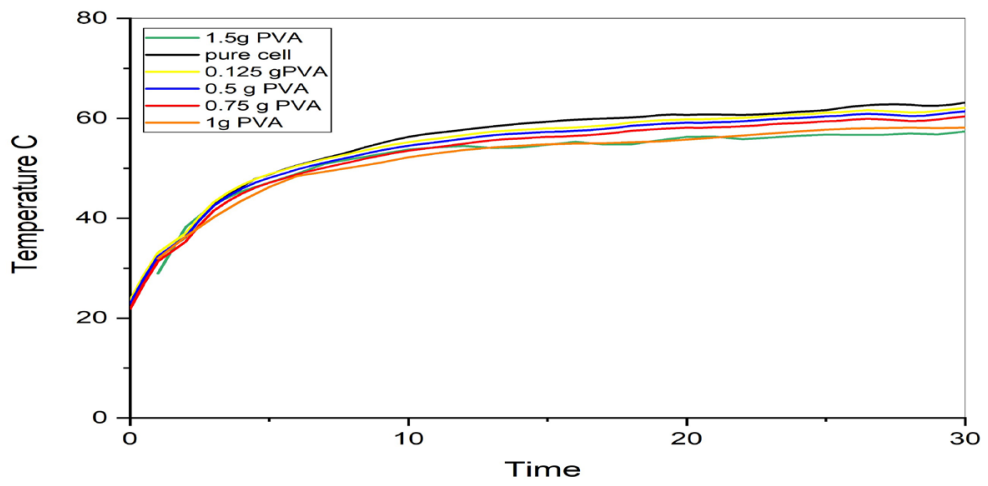

Fig.5. temperature versus time curves for bare and coating cells with different concentrations.

\subsection{I-V curve characteristics}

One of the most significant parameters affecting solar cell efficiency is rising temperature. Because Increasing the operating temperature of the PV module has significantly impacted the PV module by reducing its voltage $[14,18]$. The experimental data in table. 3 was extracted from the solar cell module type (PROVA-200A); after the end time test $1800 \mathrm{secs}$, and reach the solar cells steady-state condition, all the solar cells have various temperatures.

This data observes the impact of temperature on the efficiency of solar cells. The lower efficiency was for a pure solar cell with a high-temperature surface which was $15.07 \%$, and the best efficiency was obtained with a lower temperature surface and the best concentration of polyvinyl alcohol, which was $18.99 \%$. Fig. 6 show the I-V characteristics curves for crystalline silicon solar cells. Observe the effect of different PVA concentrations on the solar cell's parameters .that test is done after the solar cell reaches the steady-state. 
Table.3. I-V characteristics for mc-Si solar cells with and without coating,

\begin{tabular}{|c|c|c|c|c|c|}
\hline samples & Concentration & Voc $(\mathbf{V})$ & $\mathbf{I}_{\text {SC }}(\mathbf{m A})$ & FF & $\eta(\mathbf{\%})$ \\
\hline S1 & Pure & 0.545 & 279.8 & 0.692 & $15.07 \%$ \\
\hline S2 & $1 \mathrm{~g}($ PVA $)$ & 0.533 & 376.8 & 0.633 & 18.16 \\
\hline S3 & $1.5 \mathrm{~g}($ PVA $)$ & 0.566 & 330.2 & 0.711 & $18.99 \%$ \\
\hline S4 & $0.75 \mathrm{~g}(\mathrm{PVA})$ & 0.556 & 321.5 & 0.702 & $17.94 \%$ \\
\hline S5 & $0.5 \mathrm{~g}(\mathrm{PVA})$ & 0.592 & 0.592 & 0.535 & $17.18 \%$ \\
\hline S6 & $0.125 \mathrm{~g}(\mathrm{PVA})$ & 0.556 & 305.4 & 0.670 & $16.26 \%$ \\
\hline
\end{tabular}

Table.3. I-V characteristics for mc-Si solar cells with and without coating,

\begin{tabular}{|c|c|c|c|c|c|}
\hline samples & Concentration & Voc $(\mathbf{V})$ & $\mathbf{I}_{\mathbf{S C}}(\mathbf{m A})$ & $\mathbf{F F}$ & $\eta(\mathbf{\%})$ \\
\hline S1 & Pure & 0.545 & 279.8 & 0.692 & $15.07 \%$ \\
\hline S2 & $1 \mathrm{~g}($ PVA $)$ & 0.533 & 376.8 & 0.633 & 18.16 \\
\hline S3 & $1.5 \mathrm{~g}($ PVA $)$ & 0.566 & 330.2 & 0.711 & $18.99 \%$ \\
\hline S4 & $0.75 \mathrm{~g}($ PVA $)$ & 0.556 & 321.5 & 0.702 & $17.94 \%$ \\
\hline S5 & $0.5 \mathrm{~g}($ PVA $)$ & 0.592 & 0.592 & 0.535 & $17.18 \%$ \\
\hline S6 & $0.125 \mathrm{~g}($ PVA $)$ & 0.556 & 305.4 & 0.670 & $16.26 \%$ \\
\hline
\end{tabular}

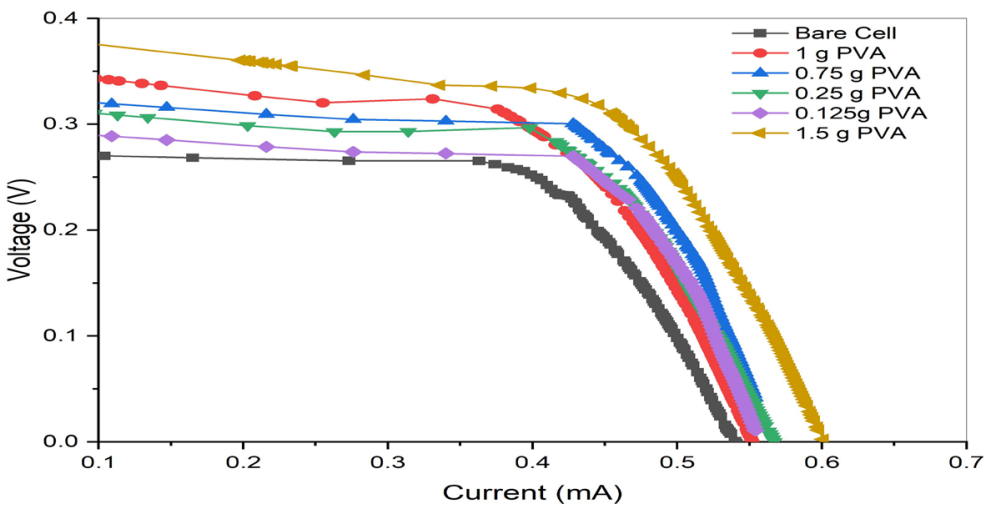

Fig.6. I-V characteristics for Bare and coating solar cells.

\section{Conclusions}

In this research, polyvinyl-alcohol was used as a coating thin film on silicon substrate by dip-coating technique. The result obtained was these thin films made as ultraviolet masking and, thus, it made an excellent solar cell's temperature regulation. Because of the apparent effect of ultraviolet rays on the temperature rise of the solar cell's surface, the photon's energy within this wavelength range of the ultraviolet rays possesses high frequencies with high photon energy that exceeds the mc-si cell's energy gap. Thus this difference in energy harms raising the temperature of the solar cell. Temperature controlling was positively influenced the improvement of the solar cell's performance. Because increasing the operating temperature of the PV module has significantly impacted the PV module by reducing its voltage. $1.5 \mathrm{~g}$ was the best concentration of the polymer 
polyvinyl-alcohol to creating the best thin-film as so on. The best temperature difference was $4.5^{\circ} \mathrm{C}$ between the coating and un-coting solar cells.

\section{References}

1. E. Radziemska, Renewable Energy 28, 1 (2003)

2. A. Mohammad Bagher, American Journal of Optics and Photonics 3, 94 (2015)

3. R. P. Chahal, S. Mahendia, A. K. Tomar, and S. Kumar, Applied Surface Science 343, 160 (2015)

4. H. Takele, S. Jebril, T. Strunskus, V. Zaporojchenko, R. Adelung, and F. Faupel, Applied Physics A 92, 345 (2008)

5. V. Kaler, U. Pandel, and R. K. Duchaniya, in Materials Today: Proceedings (2018), pp. 6279-6287

6. R. Singh, S. G. Kulkarni, and S. S. Channe, Polymer Bulletin 70, 1251 (2013)

7. M. Aslam, M. A. Kalyar, and Z. A. Raza, Polymer Engineering \& Science 58, 2119 (2018)

8. H. Karami and A. Mohammadi, Int. J. Electrochem. Sci 10, 7392 (2015)

9. M. T. Ramesan, P. Jayakrishnan, T. Anilkumar, and G. Mathew, Journal of Materials Science: Materials in Electronics 29, 1992 (2018)

10. M. T. Ramesan, P. Jayakrishnan, T. K. Manojkumar, and G. Mathew, Materials Research Express 5, (2018)

11. T. A. M.T. Ramesan, Chippy Jose, P. Jayakrishnan, Polymer Composites 39, 38 (2018)

12. S. Mahendia, A. K. Tomar, R. P. Chahal, P. Goyal, and S. Kumar, Journal of Physics D: Applied Physics 44, 205105 (2011)

13. S. S. Samanta, M. S. Shinde, and R. S. Patil, 57, 53 (2016)

14. K. Rakesh Tej Kumar, M. Ramakrishna, and G. Durga Sukumar, International Journal of Energy Research 42, 2305 (2018)

15. D. M. Hachim, Q. A. Abed, and F. Kamil, Energy Sources, Part A: Recovery, Utilization, and Environmental Effects 1, 1 (2020)

16. Q. A. H. Al-naser, N. M. A. Al-barghoothi, and N. A. S. Al-ali, International Journal of Engineering, Business and Enterprise Applications (IJEBEA) 108 (2013)

17. P. Singh and N. M. Ravindra, Solar Energy Materials and Solar Cells 101, 36 (2012)

18. S. Chander, A. Purohit, A. Sharma, Arvind, S. P. Nehra, and M. S. Dhaka, Energy Reports 1, 104 (2015) 